\title{
Association between $(\mathrm{AC})_{n}$ dinucleotide repeat polymorphism at the $5^{\prime}$-end of the aldose reductase gene and diabetic nephropathy: a meta-analysis
}

\author{
Mingtong Xu, Xiaochao Chen ${ }^{1}$, Li Yan, Hua Cheng and Weiqing Chen ${ }^{2}$ \\ Department of Endocrinology, the Second Affiliated Hospital, Sun Yat-Sen University, 107 Yanjiang Road, Guangzhou 510120, People's Republic of China \\ 'Department of Cardiology, the Fifth Affiliated Hospital, Sun Yat-Sen University, 52 Meihua Road, Zhuhai 519000, People's Republic of China \\ ${ }^{2}$ Department of Epidemiology, the College of Public Health, Sun Yat-Sen University, 72 Zhongshan Road, Guangzhou 510080, People's Republic of China \\ (Correspondence should be addressed to X Chen; Email: cxcoffice@21cn.com)
}

\begin{abstract}
Association between the $(\mathrm{AC})_{n}$ dinucleotide repeat polymorphism at the $5^{\prime}$-end of the aldose reductase gene and the occurrence of diabetic nephropathy was conducted. We examined eight studies consisting of ten Caucasian type 1 diabetes mellitus case-control comparisons and eight studies consisting of nine type 2 diabetes mellitus case-control comparisons, which were based on our inclusion criterion and available in the literature. The meta-analysis demonstrated a large heterogeneity among the studies on the type 1 diabetic subjects and a significant association was observed between the $(\mathrm{AC})_{n}$ dinucleotide repeat polymorphism at the $5^{\prime}$-end of the aldose reductase gene and diabetic nephropathy. The $Z-2$ allele appeared to be a genetic risk factor for susceptibility to diabetic nephropathy with a random effects odds ratio (OR) of 1.40 (95\% confidence interval, $\mathrm{Cl}(1 \cdot 07,1 \cdot 84))$. The $Z+2$ allele showed a protective effect on diabetic nephropathy with a random effects OR of $0.77(95 \% \mathrm{Cl}(0.65,0.91))$. The meta-analysis, however, showed no association between the genetic polymorphism and diabetic nephropathy in type 2 diabetic subjects. Neither the risk $Z-2$ allele nor the protective $Z+2$ allele in type 1 diabetic subjects appeared to have an effect on nephropathy in type 2 diabetic subjects, while their fixed effects OR was $1.09(95 \% \mathrm{Cl}(0.96,1 \cdot 22))$ and $0.88(95 \% \mathrm{Cl}(0.67,1 \cdot 15))$ respectively. The current meta-analysis demonstrated a correlation between the $(\mathrm{AC})_{n}$ dinucleotide repeat polymorphism and the occurrence of diabetic nephropathy in Caucasian type 1 diabetic subjects in contrast to type 2 diabetic subject population in which such an association could not be demonstrated.
\end{abstract}

Journal of Molecular Endocrinology (2008) 40, 243-251

\section{Introduction}

Diabetic nephropathy is a severe long-term complication of both type 1 and 2 diabetes mellitus, which is considered as one of the leading causes of end-stage renal disease requiring either dialysis or renal transplantation. Although the precise process that causes diabetic nephropathy remains unknown, some studies suggested that environmental risk factors, including the duration of disease, quality of glycaemic control, hypertension and hyperlipidaemia, contribute to the pathogenesis of the microvascular damage, which is associated with diabetic nephropathy. On the other hand, accumulated evidence supported the role of genetic factors in the susceptibility to diabetic nephropathy in family-based, case-control and epidemiological studies (Chowdhury et al. 1999).

An increased flux of glucose through the polyol pathway, in which aldose reductase (ALR2) is the first and rate-limiting enzyme, is one of the main mechanisms implicated in the progression of diabetic microvascular complications (Srivastava et al. 2005). The ALR2 gene localized on chromosome 7q35 extends over 18 kilobases and contains ten exons that code for a $1384 \mathrm{bp}$ mRNA. An $(\mathrm{AC})_{n}$ dinucleotide repeat polymorphism in the promoter region and some single nucleotide polymorphisms (SNPs) have been identified in the ALR2 gene (Demaine 2003). After Ko et al. (1995) initially reported that the $(\mathrm{AC})_{n}$ repeat polymorphism was associated with early onset of retinopathy in Chinese patients with type 2 diabetes, the association between the ALR2 gene polymorphisms and chronic microvascular complications in patients either with type 1 or type 2 diabetes had been examined in several populations; however, some studies reported inconsistent observations (Heesom et al. 1997, Dyer et al. 1999, Kao et al. 1999, Maeda et al. 1999).

The most common allele has been designated as $\mathrm{Z}$, which consists of $(\mathrm{AC})_{24}$ repeats, whilst the $\mathrm{Z}-2$ allele and conversely the $\mathrm{Z}+2$ allele contain $(\mathrm{AC})_{23}$ and $(\mathrm{AC})_{25}$ repeats respectively. Because of the low frequencies of the variant ALR2 microsatellite alleles, 
only the $\mathrm{Z}-2$ allele was considered as a risk allele, whereas the $\mathrm{Z}+2$ allele was considered a protective allele in some eligible studies. To address the ambiguities raised by the inconsistencies among molecular genetic studies, it is recommended to apply statistical analyses-mediated meta-analyses. Herein, we examined whether the aggregate evidence across all available studies provides evidence of statistical significance. Thus, to evaluate the putative association between diabetic nephropathy and the $A L R 2$ gene $(\mathrm{AC})_{n}$ repeat allele, we applied meta-analysis to all available and eligible case-control studies.

\section{Materials and methods}

\section{Eligible criteria}

We considered all studies that examined the association of the ALR2 polymorphism with diabetic nephropathy. Sources included Medline and Embase (last search update was performed in April 2007). The search strategy was based on combinations of the terms diabetic nephropathy, aldose reductase, polymorphism, allele and genetics. The references cited in the retrieved publications were also screened (the final update was April 2007). The eligible criteria included case-control study that determined the distribution of ALR2 genotypes in diabetic nephropathy cases as well as in a concurrent control group of microvascular complication-free subjects with diabetes using a molecular method for genotyping. We excluded studies or subgroups thereof with familial linkage designs.

\section{Data extraction}

Two investigators independently extracted the data and reached consensus on all items. In all these identified studies, diabetic subjects with nephropathy were considered as 'cases' while those subjects with longterm diabetes without nephropathy served as 'controls'. In addition, the following information was sought from each study: authors, journal and year of publication, country of origin, number of cases and controls, racial descent of the study population and frequencies of alleles. For studies where subjects of different racial descent were included, data were extracted separately for each race. Furthermore, we examined whether matching had been used, whether there was specific mention of blinding of the personnel who performed the genotyping to the clinical status of the subjects and whether the genotyping method had been validated. For publications that did not contain complete information on the distribution of genotypes in cases and controls, we obtained the pertinent data directly from primary study investigators.

\section{Meta-analysis}

In the meta-analysis, diabetic nephropathy patients were compared with diabetic controls without nephropathy for the frequencies of the $\mathrm{Z}-2$ allele (reported as a risk allele) and the frequencies of the $\mathrm{Z}+2$ allele (reported as a protective allele) in some studies, including both type 1 and 2 diabetic subjects. Because the case-control studies were involved, the random effects odd ratio (OR) was used as the metric of choice. For each typical contrast, we estimated the betweenstudy heterogeneity across all eligible comparisons using $\chi^{2}$-based $Q$ statistics. Heterogeneity was considered significant for $P<0 \cdot 05$. Data were combined using both fixed effects (Mantel-Haenszel algorithm) and random effects (Der Simonian and Laird algorithm). Random effects incorporate an estimate of the between-study variance and tend to provide wider confidence intervals (CIs), when the results of the constituent studies differ among themselves. In the absence of between-study heterogeneity, the two methods provide identical results. Random effects are more appropriate when heterogeneity is present.

Inverted funnel plots were used to evaluate whether the magnitude of the observed association was related to the variance of each study. We also performed cumulative meta-analysis to evaluate whether the summary OR and its $95 \%$ CIs of the frequency of the $\mathrm{Z}-2$ and $\mathrm{Z}+2$ alleles changed over time as more data accumulated. Analyses were conducted using the SPSS, version 10.0, software (SPSS, Inc., Chicago, IL, USA), and Review Manage (version 4.2; Oxford, England). All $P$ values are two tailed.

\section{Results}

\section{Eligible studies on diabetic nephropathy in type 1 diabetes mellitus}

Eight studies (Heesom et al. 1997, Shah et al. 1998, Dyer et al. 1999, Isermann et al. 2000, Moczulski et al. 2000, Neamat-Allah et al. 2001, Ng et al. 2001, Lajer et al. 2004) evaluated the association between the $A L R 2$ gene (AC) $n$ polymorphism and the occurrence of diabetic nephropathy in type 1 diabetic subjects. In the study by Shah et al. (1998), one subgroup from the US and the other from Italy were included. Neamat-Allah et al. (2001) also included two distinct racial descents, one from North Ireland and the other from the UK. Thus, subjects in seven out of eight studies were all Caucasians, and in the study conducted by Moczulski et al. (2000), $90 \%$ of the subjects were Caucasians. Specific matching for age at diagnosis or examination and duration of diabetes was described in six comparisons (Heesom et al. 1997, Shah et al. 1998, Moczulski et al. 2000, Neamat-Allah et al. 2001, Lajer et al. 2004), 
and in the other four comparisons (Dyer et al. 1999, Isermann et al. 2000, Neamat-Allah et al. 2001, Ng et al. 2001), this information was not mentioned. Detection of albumin in urine was used to diagnose for diabetic nephropathy in all of the eligible studies. Appropriate molecular methods for genotyping were used in all of the eligible studies and the allele assignment was verified by an independent observer in the majority of the eligible studies.

\section{Eligible studies about diabetic nephropathy in type 2 diabetic subjects}

Eight studies (Maeda et al. 1999, Moczulski et al. 1999, Neamat-Allah et al. 2001, Liu et al. 2002, Park et al. 2002, Wang et al. 2003, Zhao et al. 2004, Wolford et al. 2006) about the relationship between the ALR2 gene (AC) ${ }_{n}$ polymorphism and diabetic nephropathy susceptibility were identified. The study conducted by Neamat-Allah et al. (2001) contained subjects of two different ethnic descents. Five comparisons involved Asian subjects, including Chinese (Liu et al. 2002, Wang et al. 2003, Zhao et al. 2004), Japanese (Maeda et al. 1999) and Korean (Park et al. 2002), two of them involved Pima Indian (Neamat-Allah et al. 2001, Wolford et al. 2006) and the other two involved Caucasian (Moczulski et al. 1999, Neamat-Allah et al. 2001). Age at diagnosis or examination and duration of diabetes were matched in five comparisons (Maeda et al. 1999, Moczulski et al. 1999, Park et al. 2002, Zhao et al. 2004, Wolford et al. 2006), and in three comparisons (Neamat-Allah et al. 2001, Liu et al. 2002, Wang et al. 2003), the subjects with nephropathy were older and/or had longer duration of diabetes than their controls. Information of age and diabetic duration in the Pima Indian group from the US (Neamat-Allah et al. 2001) was not mentioned. In four studies (Liu et al. 2002, Park et al. 2002, Wang et al. 2003, Zhao et al. 2004), subjects with nephropathy exhibited a higher proportion of hypertension or average level of blood pressure than non-nephropathy controls. Except for the study by Zhao et al. (2004) in which autopsy was used, diabetic nephropathy was diagnosed via the detection of the level of albumin in urine. Appropriate molecular methods for genotyping were used in all of the eligible studies and the allele assignment was verified by an independent observer in the majority of the eligible studies.

\section{Meta-analysis databases}

A database was established according to the extracted information from each eligible study. Table 1 lists the characteristics of the eligible studies involving type 1 diabetic subjects, and Table 2 lists the characteristics of the eligible studies involving type 2 diabetic subjects.

$\frac{T}{z}$

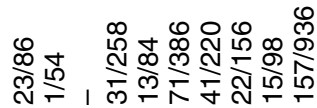

王

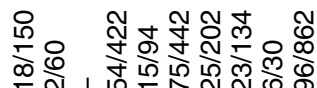

I

@

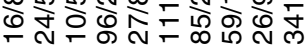

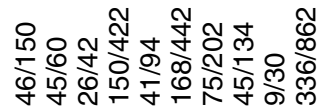

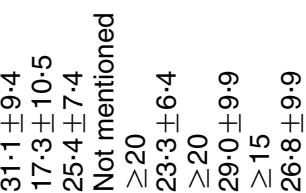

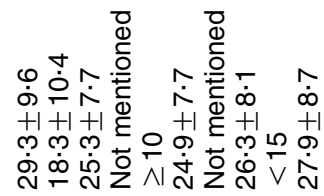

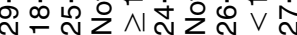

$\frac{\text { I }}{\text { z }}$

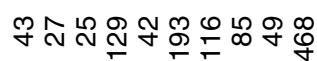

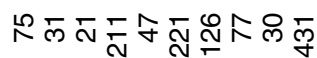
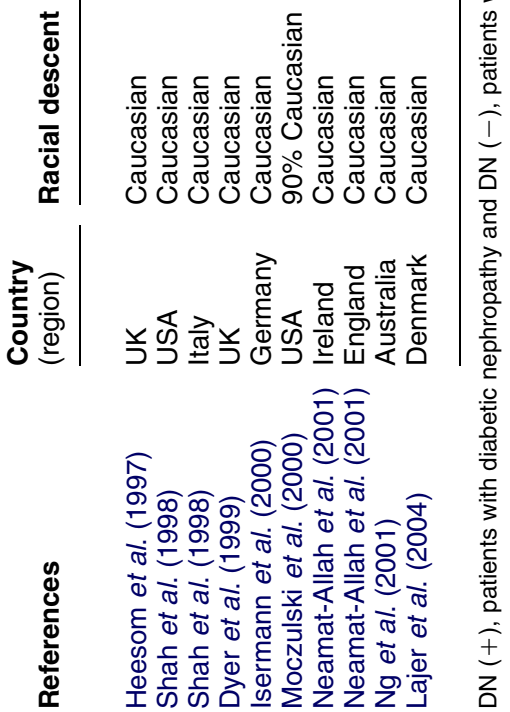


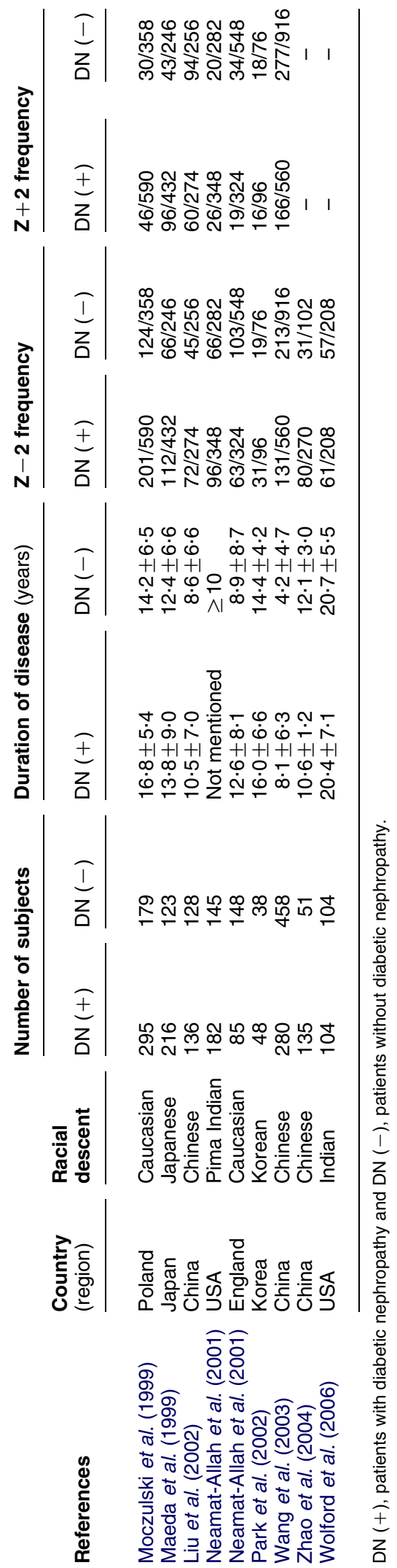

Up to ten alleles of the $5^{\prime}$-end ALR2 locus have been detected in different populations. Because of the low frequencies of the variant ALR2 microsatellite alleles, only the $\mathrm{Z}-2$ allele was considered as a risk allele and the $\mathrm{Z}+2$ allele was considered as a protective allele in some eligible studies. There were a total of ten subjects with type 1 diabetes mellitus with nephropathy casecontrol comparisons, including 1270 cases and 1177 controls. Nine comparisons consisting of 1481 cases and 1374 controls were about the relationship between the gene polymorphism and nephropathy in type 2 diabetes.

\section{Quantitative synthesis}

There was a significant between-study heterogeneity in association of the $\mathrm{Z}-2$ allele with nephropathy among the studies on type 1 diabetic $\left(\chi^{2}=32 \cdot 80, P=0 \cdot 0001\right)$. Four individual comparisons had positive results and the remaining six had negative results. The summary OR for association of $\mathrm{Z}-2$ allele with diabetic nephropathy by random effects was 1.40 and was statistically significant (95\% CI $(1 \cdot 07,1 \cdot 84), P=0 \cdot 01)$. The result of the metaanalysis on the association between the $\mathrm{Z}+2$ allele and diabetic nephropathy demonstrated a fixed effects summary OR of $0.77(95 \%$ CI $(0 \cdot 65,0 \cdot 91), P=0 \cdot 002)$ without between-study heterogeneity $\left(\chi^{2}=14 \cdot 52\right.$, $P=0 \cdot 07$; Fig. 1).

Conversely, in studies involving type 2 diabetic subjects, there was no significant association between the $\mathrm{Z}-2$ allele and susceptibility of diabetic nephropathy. Although the subjects were from different ethnic groups, there was no significant between-study heterogeneity among individual studies $\left(\chi^{2}=6 \cdot 94, P=0 \cdot 54\right)$. The fixed effects combined OR of $\mathrm{Z}-2$ to susceptibility was $1.09(95 \%$ CI $(0.96,1 \cdot 22), P=0 \cdot 18)$, and the random effects combined $\mathrm{OR}$ of $\mathrm{Z}+2$ allele was $0 \cdot 88$ $(95 \%$ CI $(0.67,1 \cdot 15), P=0.35)$ with significant heterogeneity among individual studies $\left(\chi^{2}=15 \cdot 56\right.$, $P=0 \cdot 02$; Fig. 2).

\section{Potential bias}

Cumulative meta-analysis for the $\mathrm{Z}-2$ allelic frequency showed that the pooled OR of $Z-2$ to susceptibility to diabetic nephropathy in type 1 diabetic subjects decreased from 3.08 at the end of 1998, 2.05 at the end of 1999, 1.94 at the end of 2000 and to 1.50 at the end of 2001. In type 2 diabetic subjects, the pooled OR of $\mathrm{Z}-2$ to susceptibility to diabetic nephropathy was stable at a fixed level of around 1.0 $(0.97$ at the end of $1999,1 \cdot 04$ at the end of 2001, $1 \cdot 13$ at the end of 2002, 1.09 at the end of 2003 and 1.08 at the end of 2004). The inverted funnel plots are shown in Figs 3 and 4. 


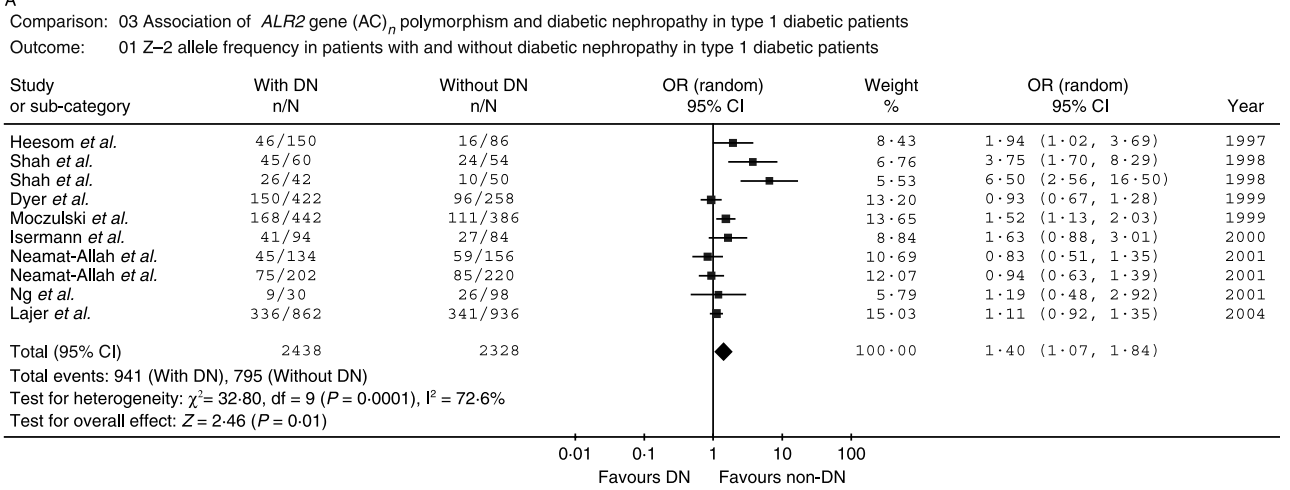
Comparison: 03 Association of $A L R 2$ gene $(A C)_{n}$ polymorphism and diabetic nephropathy in type 1 diabetic patients Outcome: $\quad 02 \mathrm{Z}+2$ allele frequency in patients with and without diabetic nephropathy in type 1 diabetic patients

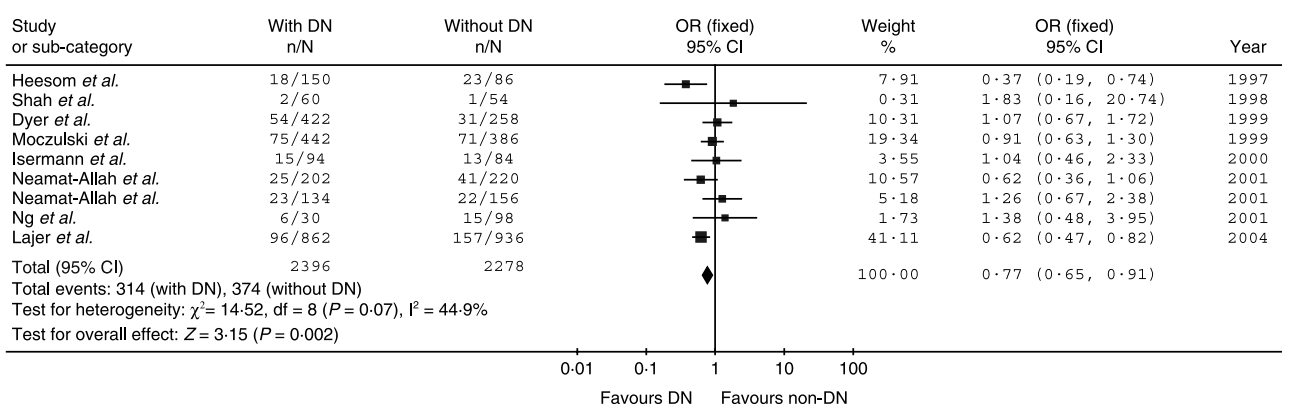

Figure 1 Meta-analysis of the association between the $A L R 2$ gene $(A C)_{n}$ polymorphism and susceptibility to diabetic nephropathy in type 1 diabetic subjects. Each study is shown by a point estimate of the OR and the accompanying $95 \% \mathrm{Cl}$. (A) $Z-2$ allele and (B) $Z+2$ allele. DN, diabetic nephropathy.

\section{Discussion}

ALR2 is a monomeric-reduced NADPH-dependent enzyme and a member of aldo-keto reductase superfamily. The enzyme was first described in 1956 by Hers (1956) to exhibit a glucose-reducing activity. It is the first enzyme in the polyol pathway and converts glucose to sorbitol, which is subsequently transformed to fructose by sorbitol dehydrogenase. It has been demonstrated that during a hyperglycaemic event, the elevated glucose level enhances ALR2 activity, thereby increasing the glucose flux through the polyol pathway that impacts other NADPH-dependent enzymes shown to play a key role in long-term diabetic onset complications such as neuropathy and nephropathy (Hodgkinson et al. 2001). Furthermore, in peripheral blood monocytes from patients with diabetic nephropathy, the ALR2 mRNA and ALR2 protein levels were significantly elevated (Shah et al. 1997). Therefore, inhibition of ALR2 expression may offer patients suffering from diabetes mellitus a viable therapeutic measure against the debilitating pathologies associated with chronic hyperglycaemia. Recently, some genetic variations in the ALR2 gene located on chromosome $7 \mathrm{q} 35$ were reported, including two common polymorphisms such as an $(\mathrm{AC})_{\mathrm{n}}$ dinucleotide repeat microsatellite and a $\mathrm{C}(-106) \mathrm{T} \mathrm{SNP}$, and examined for their putative association with diabetic nephropathy in several populations (Demaine 2003).

Here, we conducted a meta-analysis and showed that a small, but statistically significant association exists between the occurrence of diabetic nephropathy and (AC) ${ }_{n}$ microsatellite polymorphism at the $5^{\prime}$-end of ALR2 in type 1 diabetic subjects. This association was statistically significant in four out of ten individual eligible case-control comparisons. The $\mathrm{Z}-2$ allele is likely to be a genetic risk factor $(\mathrm{OR}=1 \cdot 40)$, while the $\mathrm{Z}+2$ allele might exhibit some protective role for susceptibility to diabetic nephropathy in type 1 diabetic patients $(\mathrm{OR}=0 \cdot 77)$. However, there has been some heterogeneity about $\mathrm{Z}-2$ allele among the results of various studies in type 1 diabetic subjects $\left(\chi^{2}=32 \cdot 80\right.$, $P=0 \cdot 0001)$. Furthermore, the meta-analysis of nine case-control comparisons in type 2 diabetic subjects demonstrated no relationship between diabetic nephropathy and the gene polymorphism of ALR2. Neither did the $\mathrm{Z}-2$ allele seem to exhibit a risk factor nor did the $\mathrm{Z}+2$ allele appear to play a role protective to susceptibility of the microvascular complication in type 2 diabetic subjects. There was no evidence for 

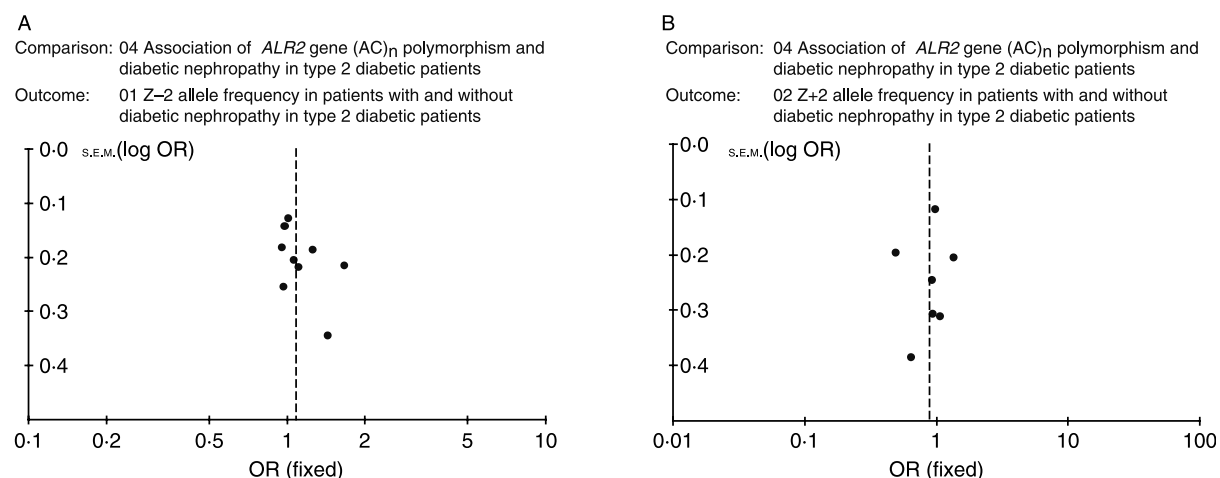

Figure 4 Funnel plot of frequencies of allele by their S.E.M. in eligible studies about type 2 diabetes. (A) Z -2 allele and (B) $Z+2$ allele.

consisting of the $\mathrm{Z}-2$ and $\mathrm{C}$ alleles corresponded to the highest relative transcriptional activity as compared with other haplotypes in HepG2 cells, suggesting that these haplotypes may have functional properties that increased the susceptibility to microvascular complications.

We estimated between-study heterogeneity using $\chi^{2}$ based $Q$ statistics and the study magnitude was expressed by study weight (inverse of variance). It was observed that the heterogeneity among the individual studies should lead to extra caution in the meta-analysis of studies on type 1 diabetic patients. With the exception of one study (Moczulski et al. 2000), the ethnicity of $10 \%$ of subjects (about 40 subjects) was not mentioned. The remaining subjects that participated in the eligible studies analysed herein were all Caucasian. Consequently, the impact of ethnicity was minor. It was noticeable that three earlier comparisons completed in 1997 and 1998 were relatively smaller in size with a study weight of $8 \cdot 4,6 \cdot 8$ and $5.5 \%$ respectively, but the pooled OR for those studies was relatively higher than those obtained in more recent studies. The significant differences in the genetic effects observed in large versus small studies or in initial versus more recent studies appeared to be common in same genetic association studies. Recently, Ioannidis et al. (2003) examined 55 meta-analyses involving genetic association studies and found that only $16 \%$ of the metaanalyses were subsequently replicated with formal statistical significance without heterogeneity or bias. Typically, large studies and subsequent research suggested weak or no association at all, compared with strong associations proposed by smaller and/or initial studies. Publication bias or time-lag bias should be considered. In this respect, small studies that show a statistically significant result tend to be published more easily and in a shorter time frame than other studies reporting 'negative' results and similar sample size and quality.

Given the wide ethnicity range of type 2 diabetic subjects, there was no heterogeneity in type 2 diabetic case-control comparison studies. When the results of the two largest individual studies reported by Moczulski et al. (1999; weight $=20 \cdot 03 \%)$ and Wang et al. (2003; weight $=24 \cdot 37 \%$ ) were compared, it was observed that the ORs of $\mathrm{Z}-2$ allele to the susceptibility of diabetic nephropathy in Polish Caucasians and Hong Kong Chinese were similar to each other, but none of those were statistically significant. The overall data demonstrate that the $\mathrm{Z}-2$ allele in ALR2 (AC) ${ }_{n}$ microsatellite polymorphism is not a genetic risk factor in the progress of nephropathy in type 2 diabetic subjects. The present meta-analysis generated a conflicting result in regard to the association between diabetic nephropathy and the gene polymorphism of ALR2 in different types of diabetes, which can be explained as follows. First, although hyperglycaemia is the common clinical characteristic of both type 1 and 2 diabetes, both types of diabetes represent a distinct disease process. Type 1 diabetes is mainly characterized by the destruction of islet $\beta$-cells by the immune system, a process determined by the activity of major histocompatibility complex (MHC)-restricted T lymphocytes. The MHC locus (human leukocyte antigen (HLA) region) is the major susceptibility interval of the disease (Park \& Eisenbarth 2001). Type 2 diabetes represents a complex and heterogeneous group of disorders, which has genetic heterogeneity underlying the common phenotypic endpoint of elevated blood glucose level, likely involving a large number of contributing genes (Tusié Luna 2005). Second, the variability in subject selection criteria is a possibly important confounding factor in studies of the two types of diabetes. In the case-control comparisons of type 1 diabetic subjects, the main clinical characteristics, including age at diagnosis or examination and the duration of diabetes, were well matched among each other. However, in some studies involving type 2 diabetic subjects, the subjects with nephropathy were older and the respective duration of diabetes was longer than their counter partners. Third, other causes, including the level of blood pressure and 
lipid levels, in addition to hyperglycaemia may contribute to the level of protein urea in type 2 diabetic patients. In several studies, either the average level of blood pressure or proportion of patients with hypertension in cases with nephropathy was obviously higher than those measured in the control subjects without nephropathy.

Furthermore, limitations of retrospective case-control studies should be considered to explain our observations. Olmos et al. (2000) reported in a progressive study that subjects with the $\mathrm{Z}-2$ allele of the $(\mathrm{AC})_{n}$ repeat had 8.9 times faster progression of another microvascular complication, retinopathy, than subjects with other alleles. In another progressive study (Olmos et al. 2006), it was observed that the other locus $\mathrm{C}(-106) \mathrm{T}$ polymorphism in ALR2 has a similar association with retinopathy. This strongly suggests a higher proportion of microvascular complications, including end-stage renal disease and even a higher mortality at the earlier stage of diabetes, in patients with risk genes as compared with those with protective genes. Niskanen et al. (1996) reported that during a 10-year follow-up study, there was a markedly increased cardiovascular mortality among type 2 diabetic patients with albuminuria. As most of the eligible studies included in the current meta-analysis selected subjects with a long-term duration of diabetes, it is likely that the association between the gene polymorphism and nephropathy is underestimated and some information might be overlooked. It is therefore advisable to conduct new studies on the association between genetic alterations and the occurrence of diabetes employing larger subject populations with different ethnicities.

In conclusion, the present meta-analysis suggested an association between the $(\mathrm{AC})_{n}$ microsatellite polymorphism at the $5^{\prime}$-end of the ALR2 gene and nephropathy in Caucasian subjects with type 1 diabetes mellitus. In addition, it was observed that the $\mathrm{Z}-2$ allele is a genetic risk factor for diabetic nephropathy, while the $\mathrm{Z}+2$ allele exhibits some protective effect in the process of the complication. There was no association when the same relationships were considered in type 2 diabetic subjects of various ethnic groups.

\section{Acknowledgements}

This work was supported in part by the Guangdong Science and Technology Project Foundation (no. 2005B3370321) and Zhuhai Municipal Science and Technology Foundation (no. PB20051015). The authors declare that there is no conflict of interest that would prejudice the impartiality of this scientific work.

\section{References}

Chowdhury TA, Dyer PH, Kumar S, Barnett AH \& Bain SC 1999 Genetic determinants of diabetic nephropathy. Clinical Science 96 221-230.

Demaine AG 2003 Polymorphisms of the aldose reductase gene and susceptibility to diabetic microvascular complications. Current Medicinal Chemistry 10 1389-1398.

Dyer PH, Chowdhury TA, Dronsfield MJ, Dunger D \& Barnett AH 1999 The $5^{\prime}$-end polymorphism of the aldose reductase gene is not associated with diabetic nephropathy in Caucasian type I diabetic patients. Diabetologia 42 1030-1031.

Heesom AE, Hibberd ML, Millward A \& Demaine AG 1997 Polymorphism in the $5^{\prime}$-end of the aldose reductase gene is strongly associated with the development of diabetic nephropathy in type I diabetes. Diabetes 46 287-291.

Hers HG 1956 The mechanism of the transformation of glucose in fructose in the seminal vesicles. Biochimica et Biophysica Acta 22 202-203.

Hodgkinson AD, Sondergaard KL, Yang B, Cross DF, Millward BA \& Deamine AG 2001 Aldose reductase expression is induced by hyperglycaemia in diabetic nephropathy. Kidney International 60 211-218.

Ioannidis JPA, Trikalinos TA, Ntzani EE \& Contopoulos-Ioannidis DG 2003 Genetic associations in large versus small studies: an empirical assessment. Lancet $\mathbf{3 6 1}$ 567-571.

Isermann B, Schmidt S, Bierhaus A, Schiekofer S, Borcea V, Ziegler R, Nawroth PP \& Ritz E 2000 (CA) ( $n$ ) dinucleotide repeat polymorphism at the $5^{\prime}$-end of the aldose reductase gene is not associated with microangiopathy in Caucasians with long-term diabetes mellitus 1. Nephrology, Dialysis, Transplantation 15 918-920.

Kao YL, Donaghue K, Chan A, Knight J \& Silink M 1999 A novel polymorphism in the aldose reductase gene promoter region is strongly associated with diabetic retinopathy in adolescents with type 1 diabetes. Diabetes 48 1338-1340.

Ko BC, Lam KS, Wat NM \& Chung SS 1995 An (A-C) $n$ dinucleotide repeat polymorphic marker at the $5^{\prime}$-end of the aldose reductase gene is associated with early-onset diabetic retinopathy in NIDDM patients. Diabetes 44 727-732.

Lajer M, Tarnow L, Fleckner J, Hansen BV, Edwards DG, Parving HH \& Boel E 2004 Association of aldose reductase gene $Z+2$ polymorphism with reduced susceptibility to diabetic nephropathy in Caucasian Type 1 diabetic patients. Diabetic Medicine 21 867-873.

Liu YF, Wat NM, Chung SS, Ko BC \& Lam KS 2002 Diabetic nephropathy is associated with the $5^{\prime}$-end dinucleotide repeat polymorphism of the aldose reductase gene in Chinese subjects with Type 2 diabetes. Diabetic Medicine 19 113-118.

Maeda S, Haneda M, Yasuda H, Tachikawa T, Isshiki K, Koya D, Terada M, Hidaka H, Kashiwagi A \& Kikkawa R 1999 Diabetic nephropathy is not associated with the dinucleotide repeat polymorphism upstream of the aldose reductase (ALR2) gene but with erythrocyte aldose reductase content in Japanese subjects with type 2 diabetes. Diabetes 48 420-422.

Moczulski DK, Burak W, Doria A, Zychma M, Zukowska-Szczechowska E, Warram JH \& Grzeszczak W 1999 The role of aldose reductase gene in the susceptibility to diabetic nephropathy in Type II (non-insulindependent) diabetes mellitus. Diabetologia 42 94-97.

Moczulski DK, Scott L, Antonellis A, Rogus JJ, Rich SS, Warram JH \& Krolewski AS 2000 Aldose reductase gene polymorphisms and susceptibility to diabetic nephropathy in Type 1 diabetes mellitus. Diabetic Medicine 17 111-118.

Neamat-Allah M, Feeney SA, Savage DA, Maxwell AP, Hanson RL, Knowler WC, EI Nahas AM, Plater ME, Shaw J, Boulton AJ et al. 2001 Analysis of the association between diabetic nephropathy and polymorphisms in the aldose reductase gene in Type 1 and Type 2 diabetes mellitus. Diabetic Medicine 18 906-914. 
Ng DP, Conn J, Chung SS \& Larkins RG 2001 Aldose reductase (AC) $(n)$ microsatellite polymorphism and diabetic microvascular complications in Caucasian Type 1 diabetes mellitus. Diabetes Research and Clinical Practice 52 21-27.

Niskanen LK, Penttila I, Parviainen M \& Uusitupa MI 1996 Evolution, risk factors, and prognostic implications of albuminuria in NIDDM. Diabetes Care 19 486-493.

Olmos P, Futers S, Acosta AM, Siegel S, Maiz A, Schiaffino R, Morales P, Diaz R, Arriagada P, Claro JC et al. 2000 (AC) 23 [Z-2] polymorphism of the aldose reductase gene and fast progression of retinopathy in Chilean type 2 diabetics. Diabetes Research and Clinical Practice 47 169-176.

Olmos P, Bastias MJ, Vollrath V, Toro L, Trincado A, Salinas P, Claro JC, Lopez JM, Acosta AM, Miquel JF et al. 2006 C (-106)T polymorphism of the aldose reductase gene and the progression rate of diabetic retinopathy. Diabetes Research and Clinical Practice $\mathbf{7 4}$ $175-182$.

Park Y \& Eisenbarth GS 2001 Genetic susceptibility factors of type 1 diabetes in Asians. Diabetes Metabolism Research and Reviews 17 2-11.

Park HK, Ahn CW, Lee GT, Kim SJ, Song YD, Lim SK, Kim KR, Huh KB \& Lee HC 2002 (AC) (n) polymorphism of aldose reductase gene and diabetic microvascular complications in type 2 diabetes mellitus. Diabetes Research and Clinical Practice 55 151-157.

Shah VO, Dorin RI, Sun Y, Braun M \& Zager PG 1997 Aldose reductase gene expression is increased in diatetic nephropathy. Journal of Clinical Endocrinology and Metabolism 82 2294-2298.

Shah VO, Scavini M, Nikolic J, Sun Y, Vai S, Griffith JK, Dorin RI, Stidlev C, Yacoub M, Vander Jagt DL et al. 1998 Z - 2 microsatellite allele is linked to increased expression of the aldose reductase gene in diabetic nephropathy. Journal of Clinical Endocrinology and Metabolism 83 2886-2891.

Srivastava SK, Ramana KV \& Bhatnagar A 2005 Role of aldose reductase and oxidative damage in diabetes and the consequent potential for therapeutic options. Endocrine Reviews 26 380-392.
Stevens MJ, Killen P, Wang P, Larkin DD \& Greene DA 2000 Overexpression of aldose reductase (AR) in human retinal pigment epithelial (RPE) cell lines is associated with a polymorphism in the AR basal promoter region. Diabetes 49 (Suppl. 1) A167.

Tusié Luna MT 2005 Genes and type 2 diabetes mellitus. Archives of Medical Research 36 210-222.

Wang Y, Ng MC, Lee SC, So WY, Tong PC, Cockram CS, Critchlev JA \& Chan JC 2003 Phenotypic heterogeneity and associations of two aldose reductase gene polymorphisms with nephropathy and retinopathy in type 2 diabetes. Diabetes Care 26 2410-2415.

Wolford JK, Yeatts KA, Red Eagle AR, Nelson RG, Knowler WC \& Hanson RL 2006 Variants in the gene encoding aldose reductase (AKR1B1) and diabetic nephropathy in American Indians. Diabetic Medicine 23 367-376.

Yang B, Millward A \& Demaine A 2003 Functional differences between the susceptibility $\mathrm{Z}-2 / \mathrm{C}-106$ and protective $\mathrm{Z}+2 / \mathrm{T}-106$ promoter region polymorphisms of the aldose reductase gene may account for the association with diabetic microvascular complications. Biochimica et Biophysica Acta 1639 1-7.

Zhao HL, Tong PC, Lai FM, Tomlinson B \& Chan JC 2004 Association of glomerulopathy with the $5^{\prime}$-end polymorphism of the aldose reductase gene and renal insufficiency in type 2 diabetic patients. Diabetes 53 2984-2991.

Zou X, Lu J \& Pan C 2000 The effect of the polymorphism of (AC) $n$ in the $5^{\prime}$-end of the aldose reductase gene on the erythrocyte aldose reductase activity in the patient with type 2 diabetes mellitus. Chinese Journal of Endocrinology and Metabolism 16 346-349.

Received in final form 28 February 2008

Accepted 12 March 2008

Made available online as an Accepted Preprint

12 March 2008 